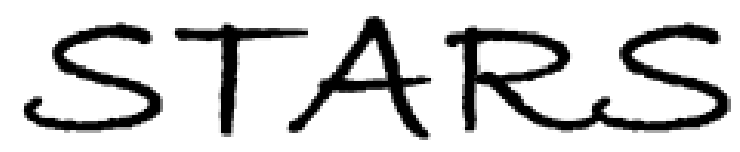

University of Central Florida

STARS

Faculty Bibliography 2000s

Faculty Bibliography

$1-1-2001$

\title{
Ion channeling effects on the focused ion beam milling of $\mathrm{Cu}$
}

B. W. Kempshall

University of Central Florida

S. M. Schwarz

University of Central Florida

B. I. Prenitzer

L. A. Giannuzzi

University of Central Florida

R. B. Irwin

See next page for additional authors

Find similar works at: https://stars.library.ucf.edu/facultybib2000

University of Central Florida Libraries http://library.ucf.edu

This Article is brought to you for free and open access by the Faculty Bibliography at STARS. It has been accepted for inclusion in Faculty Bibliography 2000 s by an authorized administrator of STARS. For more information, please contactSTARS@ucf.edu.

\section{Recommended Citation}

Kempshall, B. W.; Schwarz, S. M.; Prenitzer, B. I.; Giannuzzi, L. A.; Irwin, R. B.; and Stevie, F. A., "Ion channeling effects on the focused ion beam milling of $\mathrm{Cu}^{\prime \prime}$ (2001). Faculty Bibliography 2000s. 8065. https://stars.library.ucf.edu/facultybib2000/8065

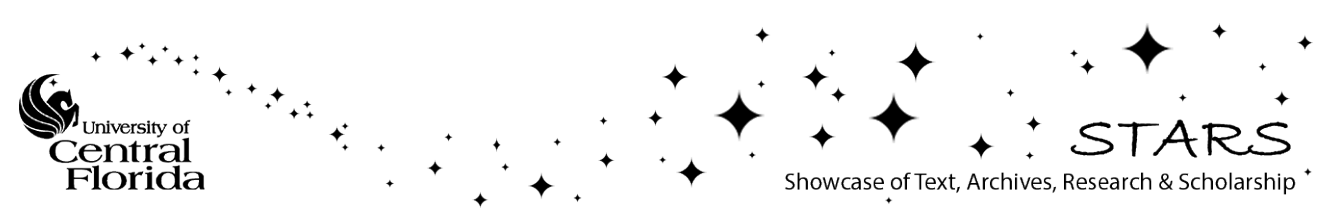




\section{Authors}

B. W. Kempshall, S. M. Schwarz, B. I. Prenitzer, L. A. Giannuzzi, R. B. Irwin, and F. A. Stevie 


\section{Ion channeling effects on the focused ion beam milling of $\mathrm{Cu}$}

B. W. Kempshall, S. M. Schwarz, B. I. Prenitzer, L. A. Giannuzzi, R. B. Irwin, and F. A. Stevie

Citation: Journal of Vacuum Science \& Technology B: Microelectronics and Nanometer Structures Processing, Measurement, and Phenomena 19, 749 (2001); doi: 10.1116/1.1368670

View online: https://doi.org/10.1116/1.1368670

View Table of Contents: https://avs.scitation.org/toc/jvn/19/3

Published by the American Institute of Physics

\section{ARTICLES YOU MAY BE INTERESTED IN}

Copper device editing: Strategy for focused ion beam milling of copper Journal of Vacuum Science \& Technology B: Microelectronics and Nanometer Structures Processing, Measurement, and Phenomena 20, 2682 (2002); https://doi.org/10.1116/1.1521736

Reducing curtaining effects in FIB/SEM applications by a goniometer stage and an image processing method Journal of Vacuum Science \& Technology B 35, 06GK01 (2017); https://doi.org/10.1116/1.4991638

A low magnification focused ion beam system with $8 \mathrm{~nm}$ spot size Journal of Vacuum Science \& Technology B: Microelectronics and Nanometer Structures Processing, Measurement, and Phenomena 9, 3079 (1991); https://doi.org/10.1116/1.585373

Reduction in hydrogen outgassing from stainless steels by a medium-temperature heat treatment Journal of Vacuum Science \& Technology A 26, 1166 (2008); https://doi.org/10.1116/1.2956625

Microscopic diamond solid-immersion-lenses fabricated around single defect centers by focused ion beam milling

Review of Scientific Instruments 85, 123703 (2014); https://doi.org/10.1063/1.4902818

Sputter yields of single- and polycrystalline metals for application in focused ion beam technology Journal of Applied Physics 105, 013542 (2009); https://doi.org/10.1063/1.3056161 


\title{
Ion channeling effects on the focused ion beam milling of $\mathrm{Cu}$
}

\author{
B. W. Kempshall ${ }^{\mathrm{a})}$ and S. M. Schwarz \\ Department of Mechanical, Materials, and Aerospace Engineering, University of Central Florida, \\ P.O. Box 162450, 4000 Central Florida Boulevard, Orlando, Florida 32816-2450
}

B. I. Prenitzer

Cirent Semiconductor (Lucent Technologies), 9333 S. John Young Parkway, Orlando, Florida 32819

L. A. Giannuzzi

Department of Mechanical, Materials, and Aerospace Engineering, University of Central Florida, P.O. Box 16250, 4000 Central Florida Boulevard, Orlando, Florida 32816-2450

\author{
R. B. Irwin and F. A. Stevie \\ Cirent Semiconductor (Lucent Technologies), 9333 S. John Young Parkway, Orlando, Florida 32819
}

(Received 8 June 2000; accepted 5 March 2001)

\begin{abstract}
The use of focused ion beam (FIB) instruments for device modification and specimen preparation has become a mainstay in the microelectronics industry and in thin film characterization. The role of the FIB as a tool to rapidly prepare high quality transmission electron microscopy specimens is particularly significant. Special attention has been given to FIB milling of $\mathrm{Cu}$ and $\mathrm{Si}$ in the microelectronics arena. Although FIB applications involving Si have been extremely successful, it has been noted that $\mathrm{Cu}$ tends to present significant challenges to FIB milling because of effects such as the development of milling induced topographical features. We show evidence that links the occurrence of milling induced topography to the severity of redeposition. Specifically, $\mathrm{Cu}$, which sputters $\sim 2.5$ times faster than $\mathrm{Si}$, exhibits an increased susceptibility to redeposition related artifacts. In addition, the effects and the mechanism of $\mathrm{Ga}^{+}$channeling in $\mathrm{Cu}$ is used to illustrate that $\mathrm{Ga}^{+}$channeling reduces the sputtering yield, improves the quality of FIB mill cuts, and improves the surface characteristics of FIB milled Cu. Finally, a technique for improving FIB milling across grain boundaries or interfaces using ion channeling contrast is suggested. (C) 2001 American Vacuum Society. [DOI: 10.1116/1.1368670]
\end{abstract}

\section{INTRODUCTION}

In recent years, focused ion beam (FIB) instruments have become extremely useful in the microelectronics industry. One of the critical applications of FIB instruments is as a specimen preparation tool for subsequent analysis in scanning electron microscopy, transmission electron microscopy (TEM), scanning transmission electron microscopy, secondary ion mass spectrometry, and scanning auger microscopy. Because of the ubiquitous use of Si-based integrated circuits (ICs) and the push toward using $\mathrm{Cu}$ in IC metallizations, interest has been directed toward the FIB milling properties of $\mathrm{Si}$ and $\mathrm{Cu}$. It is well known that $\mathrm{Si}$ exhibits exceptional FIB milling properties and that $\mathrm{Cu}$ is a bit of a conundrum. For example, Fig. 1 shows scanning electron micrographs of the difference in milling properties of FIB milled trenches in both $\mathrm{Cu}$ and $\mathrm{Si}$. $\mathrm{Cu}$ milling suffers from severe milling artifacts ranging from milling induced topography to severe redeposition effects in a confined milling geometry. ${ }^{1}$ The incorporation of $\mathrm{Cu}$ as a replacement for $\mathrm{Al}$ in the semiconductor metallization process is in progress. Therefore, it is of vital interest to investigate the milling properties of $\mathrm{Cu}$ and compare them with the well-behaved milling properties of $\mathrm{Si}$ in order to identify the critical mechanism(s) responsible for the milling artifacts and determine the optimum sputtering parameters for $\mathrm{Cu}$.

${ }^{a)}$ Electronic mail: briankempshall@sprintmail.com
The FIB instrument utilizes a finely focused ion beam from $\mathrm{a} \mathrm{Ga}^{+}$liquid metal ion source to perform imaging and milling operations. The interaction of the finely focused ion beam (FIB) with the target material will produce the ejection of secondary electrons, secondary ions, and secondary neutrals. The ions and neutrals can be ejected as individual atoms, molecules, or clusters. The imaging capability of the FIB allows the use of either the secondary electrons or the secondary ions for image formation. The milling operations are achieved through site specific sputtering of the target material. Since sputtering is the basis for the milling operations, it is important to understand the ion beam-solid interactions and the sputtering process.

An energetic incident ion, upon impact with a target material, will produce a collision cascade in the target material. If a surface atom receives enough of a normal component of momentum from the collision cascade to overcome the surface binding energy, the surface atom leaves the surface and is said to be sputtered. The factors that affect sputtering include the atomic number, energy, and angle of incidence of the ion beam, the atomic density of the target, surface binding energy of the target, and crystallographic orientation of the target. ${ }^{2}$

Another particularly interesting capability of the FIB is that it produces ion channeling contrast in the secondary electron images for polycrystalline samples. ${ }^{3,4}$ Ion channeling contrast occurs because the secondary electron yield var- 


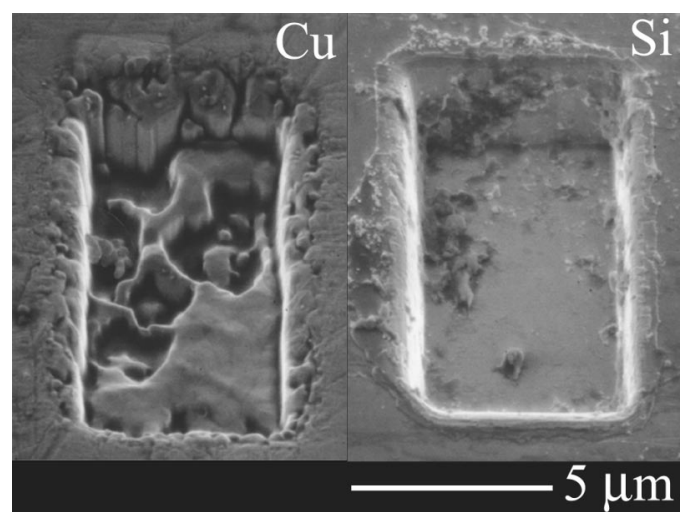

FIG. 1. Comparison between the FIB milling of $\mathrm{Cu}$ and $\mathrm{Si}$ using $30 \mathrm{keV}$ $\mathrm{Ga}^{+}$ions at $1000 \mathrm{pA}$.

ies as a function of crystallographic orientation within the sample. Channeling can occur when a crystallographic axis of a particular grain is aligned with the incident ion beam. As a result, that grain will appear darker due to a decrease in the number of secondary electrons that are emitted. An example of ion channeling contrast is shown in Fig. 2. The $\mathrm{Cu}$ grain on the right appears darker than the $\mathrm{Cu}$ grain on the left due to ion channeling contrast. This work investigates the implications of the ion channeling behavior applied to the milling properties of $\mathrm{Cu}$.

\section{EXPERIMENT}

In order to investigate the effects of ion channeling on the FIB milling of $\mathrm{Cu}$, a suitable $\mathrm{Cu}$ bicrystal was utilized. $\mathrm{A} \mathrm{Cu}$ $10^{\circ} /[100]$ twist bicrystal was mechanically polished using conventional metallographic techniques to a $1.0 \mu \mathrm{m}$ finish, and then electropolished with 1:1 mixture of phosphoric acid and deionized water at $5 \mathrm{~V}$ and $2 \mathrm{~A}$ in order to remove any surface damage. A FEI 200 TEM FIB with a $30 \mathrm{keV} \mathrm{Ga}^{+}$ion beam at $1000 \mathrm{pA}$ was used to mill a series of trenches in the $\mathrm{Cu}$ bicrystal on (i) either side of and (ii) across the $10^{\circ}$ twist grain boundary. Two $5 \mu \mathrm{m} \times 5 \mu \mathrm{m}$ trenches were milled on either side of the grain boundary and a single $24 \mu \mathrm{m}$ $\times 2 \mu \mathrm{m}$ trench was milled across the grain boundary at two different incident ion beam angles. These angles were chosen to minimize channeling in one grain $\left(\right.$ reference $0^{\circ}$ ) and maxi-

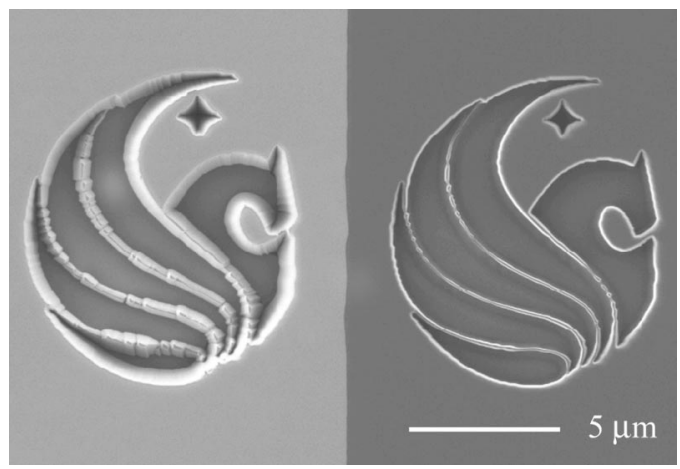

FIG. 2. An example of ion channeling contrast of a $\mathrm{Cu}$ bicrystal in the FIB using $30 \mathrm{keV} \mathrm{Ga}^{+}$ions. (a)

crystal 1

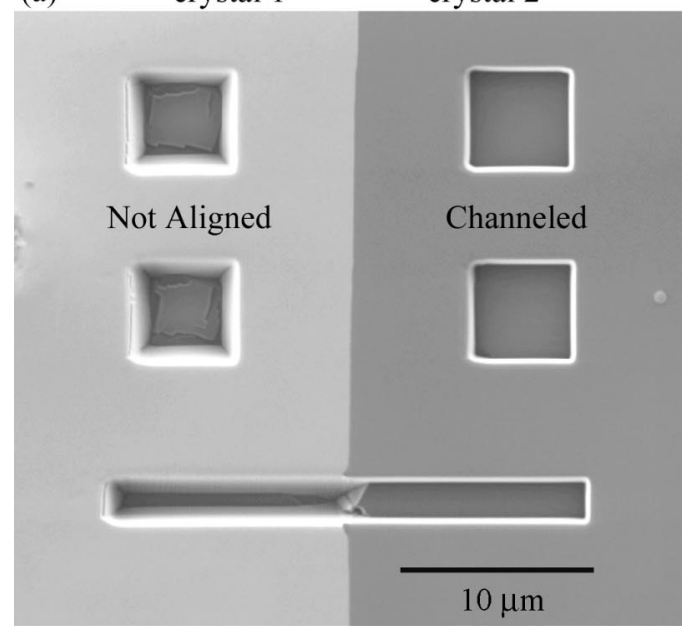

(b)

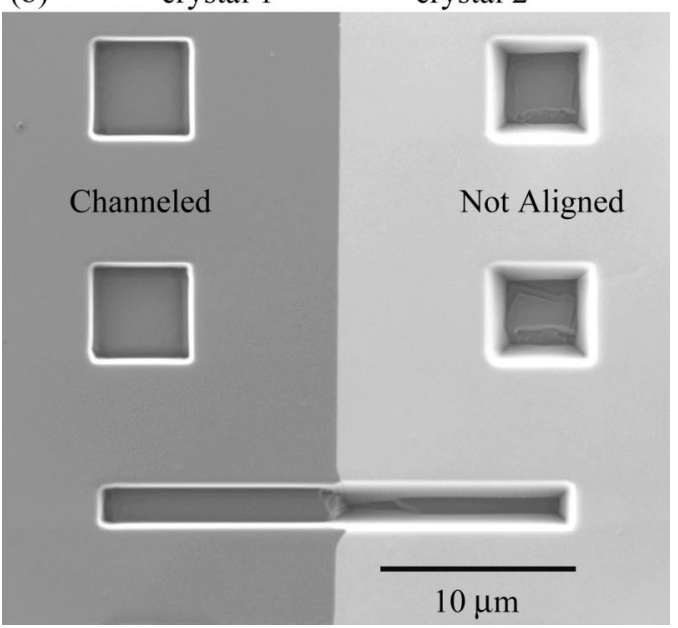

FIG. 3. Effects of channeling on the FIB milling of a $\mathrm{Cu} 10^{\circ} /[100]$ twist bicrystal at (a) $0^{\circ}$ tilt and (b) $10^{\circ}$ tilt.

mize channeling $\left(\right.$ a reference of $10^{\circ}$ ) in the second grain with respect to the beam direction. Trenches were also milled at an intermediate angle (reference $\sim 5^{\circ}$ ) to create approximately even contrast across the grain boundary.

\section{RESULTS AND DISCUSSION}

The ion channeling contrast showing a distinct change in $\mathrm{Cu}$ milling properties is evident in Fig. 3. Figure 3(a) shows the sample at $0^{\circ}$ tilt with the twist grain boundary delineating the contrast change in the center of the image. The [100] direction of the grain on the right-hand side of Fig. 3(a) is aligned with the ion beam and appears darker than the grain on the left-hand side. Alternately, in Fig. 3(b) the same sample is tilted $10^{\circ}$ so that the [100] direction of the grain on the left-hand side is now aligned with the ion beam and appears darker than the grain on the right-hand side. The flip flop in contrast is due to the effects of ion channeling contrast $^{3,4}$ previously described. The interesting feature to note in Fig. 3 is the correlation between the ion channeling contrast and the milling characteristics. When a grain is oriented to the [100] channeling direction, the milling charac- 


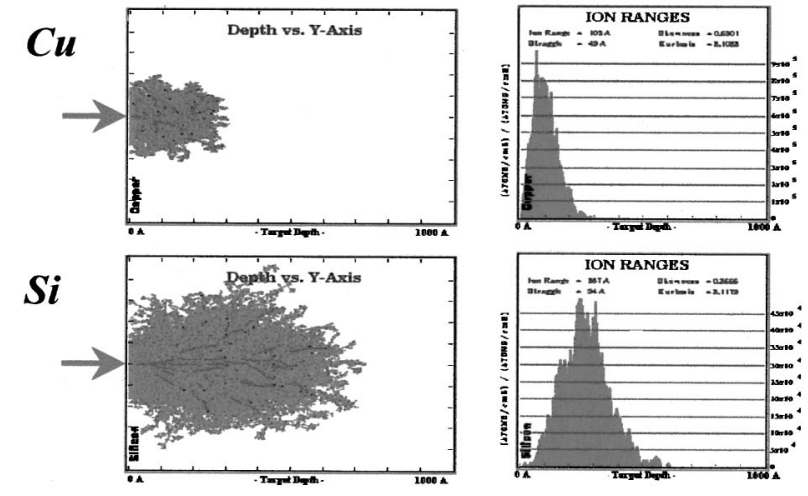

FIG. 4. TRIM simulation plots of $30 \mathrm{keV} \mathrm{Ga}^{+}$into both $\mathrm{Cu}$ and $\mathrm{Si}$ showing the differences in the size of the collision cascade and the depth distribution of $\mathrm{Ga}$ ions.

teristics of the $\mathrm{Cu}$ improve as evident by the flat trench bottoms and clean trench walls. Conversely, the trench milled in the grain that is not aligned with the [100] direction has poor milling characteristics as evident by the rough trench bottom and the sloped trench wall. Furthermore, it is clearly evident by the differing depths in the $24 \mu \mathrm{m} \times 2 \mu \mathrm{m}$ trench that the nonchanneled side of the trench mills quicker than the channeled side of the trench. Since the ion channeling contrast has been shown to be directly proportional to the sputtering yield, ${ }^{3}$ the differences in milling characteristics can be accounted for by looking at the mechanism that affects both the contrast and the sputtering yield, specifically, channeling.

It has been well established that the sputtering yield is a function of crystallographic orientation. ${ }^{3-9}$ As the ion beam becomes incident in a channeling direction, the sputtering yield will decrease. The main reason for the decrease in the sputtering yield is that the channeled ions undergo mostly electronic energy losses as opposed to nuclear energy losses and are able to penetrate deeper into the crystal lattice. The deeper penetration and the lower probability of nuclear collisions near the surface extremely limits the probability that the ion will cause a collision cascade that will contribute to the sputtering of surface atoms. TRIM ${ }^{10}$ simulation plots of 30 $\mathrm{keV} \mathrm{Ga}^{+}$incident ions into amorphous $\mathrm{Cu}$ and $\mathrm{Si}$ provide a visual comparison of the effect of the depth of penetration and resulting depth of the collision cascade as shown in Fig. 4. According to TRIM simulations, the sputtering yield for amorphous $\mathrm{Cu}$ is $\sim 2.5$ times greater than the sputtering yield for amorphous $\mathrm{Si}$. This difference is primarily due to the proximity of the collision cascade to the surface, that is, the larger number of collisions closer to the surface will enable more atoms to be sputtered. Since the FIB mills Si relatively cleanly, it is reasonable to infer that if the sputtering yield can be reduced in $\mathrm{Cu}$, then it will also mill cleanly in the FIB. Referring back to Fig. 3, the effects of redeposition are reduced and the quality of the trenches are improved in the trenches that are milled in the channeled direction because the $\mathrm{Cu}$ sputtering yield has been reduced through channeling. Assuming a constant incident ion energy, the actual magnitude of the decrease in sputtering yield depends on factors which include the specific channeling direction, the polished surface condition of the crystalline target material, ${ }^{7}$ the quality of the crystalline target material, and the collimation of the ion beam. The surface condition, the quality of the crystal, and the beam collimation all tend to lessen the effect of the decrease in the sputtering yield due to channeling. Since the surface of the $99.999 \%$ pure $\mathrm{Cu}$ bicrystal was mechanically polished, electropolished, and subjected to a well defined and collimated focused ion beam, the effects of the surface condition, crystal quality, and beam collimation on channeling are negligible in this model.

Using the Lindhard-Onderdelinden ${ }^{5,6}$ approach for monocrystalline sputtering, the channeling directions and critical angles are calculated for $30 \mathrm{keV} \mathrm{Ga}{ }^{+}$into $\mathrm{Cu}$ using the following seven equations as applied by Palmer et al. ${ }^{8}$ The channeled sputtering yield $Y_{u v w}$ is related to the amorphous sputtering yield $Y_{\text {amorph }}$ with the nonchanneled fraction $\chi_{u v w}$ and a fitting parameter $\eta_{h k l}$ as shown in Eq. (1):

$$
Y_{u v w}=\eta_{h k l} \chi_{u v w} Y_{\text {amorph }} .
$$

The amorphous sputtering yield $Y_{\text {amorph }}$ is dependent on the angle of incidence $\theta$ and the energy of the incident ion $E$. The nonchanneled fraction $\chi_{u v w}$ is just the statistical fraction of the beam that contributes to sputtering in the axial channeling direction and is dependent on the critical channeling angle $\psi_{c}$ and the incident ion energy $E$. The fitting parameter $\eta_{h k l}$ will be assumed as unity in order to analyze just the channeling effects. According to the LindhardOnderdelinden approach, the non-channeling fraction at normal incidence $\chi_{u v w}^{0}$ can be calculated using the ThomasFermi potential for the ion-atom interaction as shown in Eq. (2):

$$
\chi_{u v w}^{0}=\pi N t_{u v w}^{3 / 2}\left[\frac{3 A^{2} Z_{1} Z_{2}\left(\frac{e^{2}}{4 \pi \varepsilon_{0}}\right)}{E}\right]^{1 / 2} .
$$

The distance between atom positions along the index direction $[u v w]$ is $t_{u v w}$. The elemental charge $e$ is 1.60 $\times 10^{-19} \mathrm{C}$ and permittivity constant $\varepsilon_{0}$ is 8.85 $\times 10^{-12} \mathrm{C}^{2} / \mathrm{N}^{*} \mathrm{~m}^{2}$. The nonchanneled fraction depends on both the atomic density $N$ and the atomic number $Z_{2}$ of the target material, the atomic number $Z_{1}$ and energy $E$ of the incident ion, and the Thomas-Fermi screening length $A$ shown in Eq. (3). (Note again that this model neglects the effects of planar channeling.)

$$
A=\frac{\left(\frac{9 \pi^{2}}{128}\right)^{1 / 3} \times a_{0}}{\left(Z_{1}^{2 / 3}+Z_{2}^{2 / 3}\right)^{1 / 2}} .
$$

The Thomas-Fermi screening length $A$ depends on the atomic number of both the incident ion and the target material $Z_{1}$ and $Z_{2}$ and the Bohr radius $a_{0}$.

$$
a_{0}=\frac{\hbar^{2}}{m_{e} \frac{e^{2}}{4 \pi \varepsilon_{0}}}=0.529177 \AA .
$$


TABLE I. Calculated critical channeling angle $\psi_{c}$ and nonchanneled fraction $\chi_{0}$ for $\mathrm{Cu}$.

\begin{tabular}{cccccc}
\hline \hline & & $30 \mathrm{keV} \mathrm{Ga}^{+}$into $\mathrm{Cu}$ \\
$t_{u v w} / a$ & $t_{u v w}(\mathrm{~nm})$ & $\psi_{c}$ & $\chi_{0}$ \\
\hline$[110]$ & Angle from [100] & 0.71 & 0.26 & 9.87 & 0.13 \\
{$[100]$} & 45 & 1.00 & 0.36 & 7.61 & 0.22 \\
{$[112]$} & 90 & 1.22 & 0.44 & 6.54 & 0.30 \\
{$[130]$} & 35.3 & 1.58 & 0.57 & 5.40 & 0.44 \\
{$[111]$} & 18.4 & 1.73 & 0.63 & 5.04 & 0.50 \\
{$[123]$} & 54.7 & 1.87 & 0.68 & 4.76 & 0.57 \\
{$[114]$} & 36.7 & 2.12 & 0.77 & 4.33 & 0.68 \\
{$[120]$} & 19.5 & 2.24 & 0.81 & 4.16 & 0.74 \\
{$[150]$} & 26.6 & 2.55 & 0.92 & 3.77 & 0.90 \\
{$[125]$} & 11.4 & 2.74 & 0.99 & 3.58 & 1.00 \\
{$[113]$} & 24.1 & 3.32 & 1.20 & 3.10 & 1.34 \\
\hline \hline
\end{tabular}

Plank's constant divided by $2 \pi \hbar$ is $1.05 \times 10^{-34} \mathrm{~J} * \mathrm{~s}$ and the mass of the electron $m_{e}$ is $9.11 \times 10^{-31} \mathrm{~kg}$. With the establishment of the nonchanneled fraction at normal incidence $\chi_{u v w}^{0}$ the channeling directions can be calculated for a given energetic incident ion and a target material. Next, the angular width of the channeling directions, called the critical angle $\psi_{c}$, can be calculated.

$$
\begin{aligned}
& \psi_{c}=\left[\frac{3 A^{2} Z_{1} Z_{2}\left(\frac{e^{2}}{4 \pi \varepsilon_{0}}\right)}{E t_{u v w}^{3}}\right]^{1 / 4}, \\
& E<E_{1}=\frac{2 Z_{1} Z_{2}\left(\frac{e^{2}}{4 \pi \varepsilon_{0}}\right) t_{u v w}}{A^{2}} .
\end{aligned}
$$

Equation (5) is valid as long as the energy of the incident ion is less than $E_{1}$, which is the upper limit for Lindhard's low energy approximation according to Eq. (6). The calculated upper limit for the case of $30 \mathrm{keV} \mathrm{Ga}{ }^{+}$into $\mathrm{Cu}$ is $\sim 5.8$ $\mathrm{MeV}$. As the ion beam deviates from the direct channeling direction, the nonchanneled fraction will increase toward unity as channeling becomes less statistically possible. The polar angle resolved nonchanneled fraction is then denoted as $\chi_{u v w}$ as shown in Eq. (7).

$$
\chi_{u v w}=\frac{\chi_{u v w}^{0}}{1-\left(1-\chi_{u v w}^{0}\right)\left(\frac{\psi}{f \psi_{c}}\right)^{2}} .
$$

The polar angle from normal incidence along a channeling direction $[u v w]$ is $\psi$. The fitting parameter $f$ is included in order to accurately fit the model to experimental data.

Tables I and II summarize the calculated values for channeling in $30 \mathrm{keV} \mathrm{Ga}^{+}$irradiated $\mathrm{Cu}$ and $\mathrm{Si}$. The first column denotes the axial channeling direction for the given target. The next column is the angle between [100] and the axial channeling direction in the first column. The following two columns are the normalized distance between two lattice sites in the given axial channeling direction and the actual distance between the lattice sites, respectively. The last two columns include the calculated values for the critical angle for channeling $\psi_{c}$ and the nonchanneled fraction of incident $\mathrm{Ga}^{+}$ions $\chi_{0}$. Comparing the calculated channeling values from Tables I and II, it is evident that $30 \mathrm{keV} \mathrm{Ga}^{+}$can channel in more axial directions in $\mathrm{Si}$ than in $\mathrm{Cu}$. However, the effects of channeling on the FIB milling of $\mathrm{Si}$ are not as evident as compared with the FIB milling of $\mathrm{Cu}$. Even though the relative amounts of channeling in a given direction are similar for both $\mathrm{Si}$ and $\mathrm{Cu}$, the actual difference in

TABLE II. Calculated critical channeling angle $\psi_{c}$ and nonchanneled fraction $\chi_{0}$ for Si.

\begin{tabular}{cccccc}
\hline \hline & \multicolumn{3}{c}{} & & \\
Direction & Angle from $[100]$ & $t_{\text {uvw }} / a$ & $t_{\text {uvw }}(\mathrm{nm})$ & $\psi_{c}$ & $\chi_{0}$ \\
\hline$[110]$ & 45 & 0.71 & 0.38 & 6.39 & 0.11 \\
{$[100]$} & 90 & 1.00 & 0.54 & 4.93 & 0.19 \\
{$[112]$} & 35.3 & 1.22 & 0.67 & 4.23 & 0.25 \\
{$[111]$} & 54.7 & 1.30 & 0.71 & 4.05 & 0.27 \\
{$[130]$} & 18.4 & 1.58 & 0.86 & 3.49 & 0.37 \\
{$[123]$} & 36.7 & 1.87 & 1.02 & 3.08 & 0.47 \\
{$[114]$} & 19.5 & 2.12 & 1.15 & 2.80 & 0.57 \\
{$[120]$} & 26.6 & 2.24 & 1.21 & 2.69 & 0.62 \\
{$[113]$} & 25.2 & 2.49 & 1.35 & 2.49 & 0.73 \\
{$[150]$} & 11.4 & 2.55 & 1.38 & 2.44 & 0.75 \\
{$[125]$} & 24.1 & 2.74 & 1.49 & 2.31 & 0.84 \\
{$[221]$} & 48.2 & 3.00 & 1.63 & 2.16 & 0.96 \\
{$[140]$} & 14.0 & 4.12 & 2.24 & 1.70 & 1.55 \\
{$[331]$} & 46.5 & 4.36 & 2.37 & 1.63 & 1.69 \\
\hline \hline
\end{tabular}


(a)

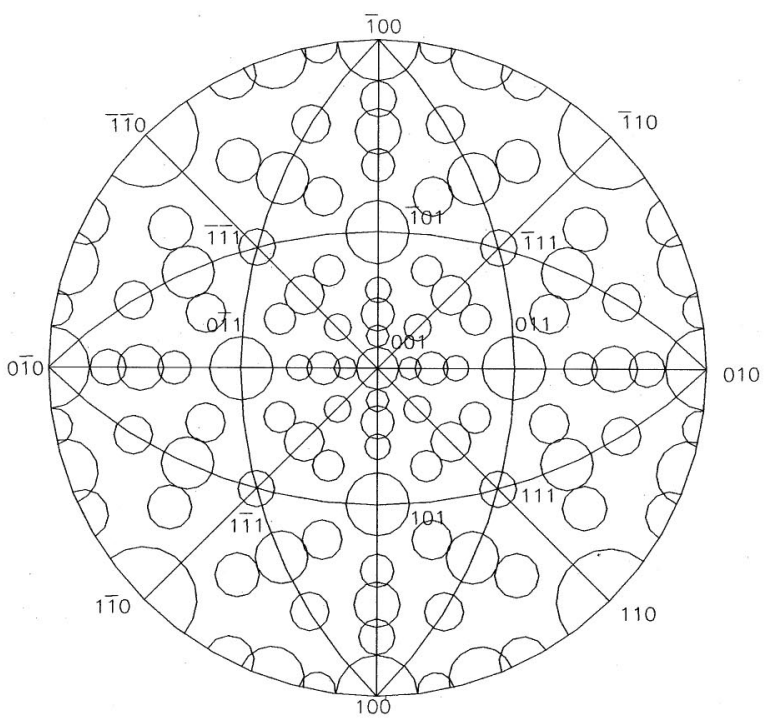

(b)
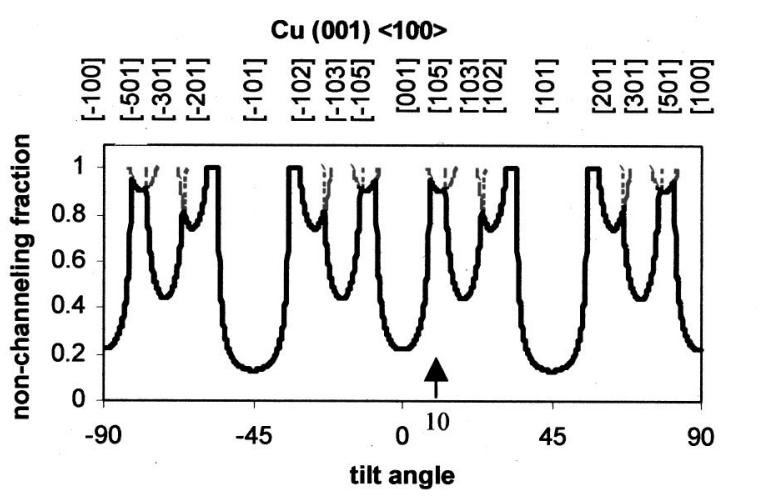

(c)

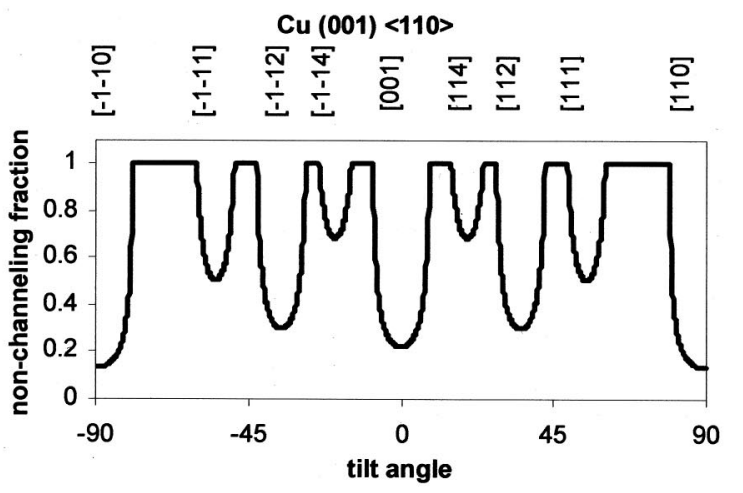

FIG. 5. (a) A [001] stereographic projection with the axial channeling directions and critical channeling angles superimposed for $30 \mathrm{keV} \mathrm{Ga}^{+}$into $\mathrm{Cu}$. The variation of the nonchanneled fraction with tilt angle along the (b) $\langle 100\rangle$ and (c) $\langle 110\rangle$ tilt directions.

the magnitudes of the sputtering yields due to channeling appears to be more important. According to TRIM simulations, the amorphous sputtering yield is $\sim 2$ for $\mathrm{Si}$ and $\sim 8$ for $\mathrm{Cu}$. Assuming a 50\% reduction in the sputtering yield due to channeling for both materials, the sputtering yield will change from a value of 2 to 1 for $\mathrm{Si}$ and from a value of 8 to 4 for $\mathrm{Cu}$. The magnitude of the change in sputtering yield is only 1 for $\mathrm{Si}$ but it is 4 for $\mathrm{Cu}$.

A [001] stereographic projection channeling map for 30 $\mathrm{keV} \mathrm{Ga}{ }^{+}$irradiated $\mathrm{Cu}$ is shown in Fig. 5(a) in order to (a) crystal 1 crystal 2

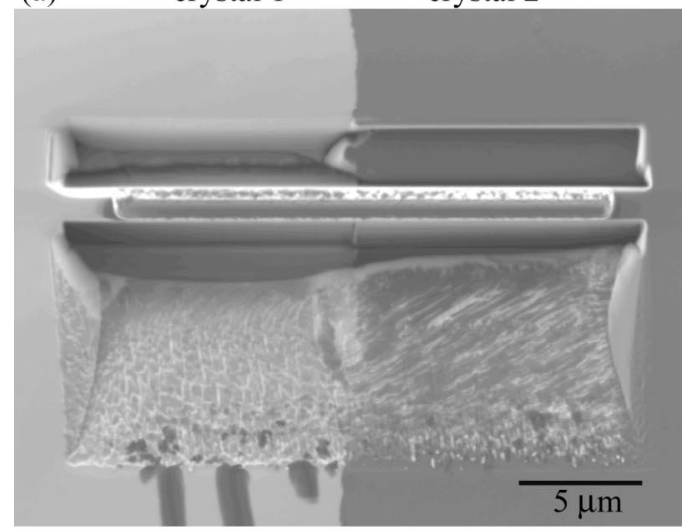

(b)

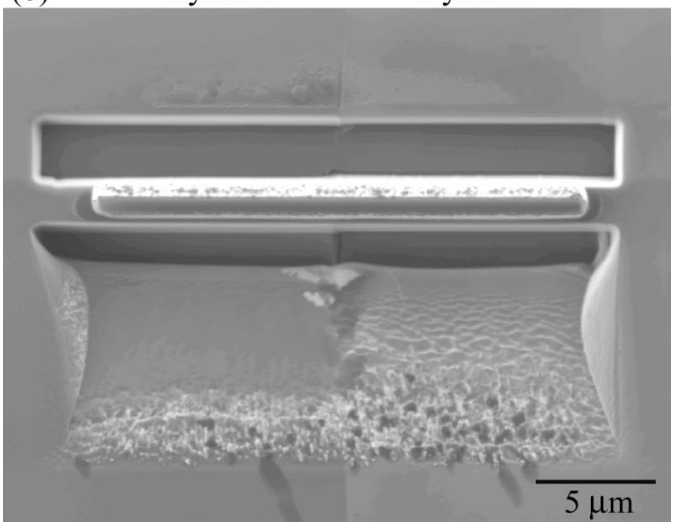

FIG. 6. Using ion channeling contrast as a guide, the differential milling in (a) is eliminated by titling the sample until the ion channeling contrast is uniform across the grain boundary (b).

visualize the data from Table I. The center of the circles correspond to the axial channeling direction and the radius of the circles is the critical angle for channeling. Figures 5(b) and 5(c) show how the calculated nonchanneled fraction changes as the crystal is tilted in the $\langle 100\rangle$ and $\langle 110\rangle$ directions. Note that Fig. 5(b) corresponds with the tilt direction in Fig. 3 and that the $10^{\circ}$ tilt from the [100] corresponds to the transition from channeling to nonchanneling in Fig. 5(b). The difference in ion channeling contrast and hence the milling quality across the grain boundary in Fig. 3 correlates well with the variation of the calculated nonchanneled fraction from $0^{\circ}$ tilt to $10^{\circ}$ tilt shown in Fig. 5(b).

The application of the effect of ion channeling on the sputtering yield and the correlation with the ion channeling contrast is shown in Fig. 6 for the preparation of a cross section TEM lift-out ${ }^{11}$ specimen from the $\mathrm{Cu}$ bicrystal interface. When the ion channeling contrast across the boundary is not uniform as shown in Fig. 6(a), the result is differential sputtering as well as trench wall sloping from redeposition on half of the specimen. Since the TEM specimen must be a uniform thickness, a modified milling technique must be employed in order to achieve a quality TEM lift-out specimen. Using the ion channeling contrast as a guide, the sample can be tilted a few degrees until the ion channeling contrast across the boundary is uniform as shown in Fig. 6(b). The 
differential sputtering is eliminated and the effects of redeposition have been reduced in order to achieve the desired uniform thickness of the specimen.

\section{SUMMARY}

The FIB milling of $\mathrm{Cu}$ tends to present interesting problems that are not experienced with FIB milling of other materials, such as Si. The effects of ion channeling on the FIB milling of $\mathrm{Cu}$ can be used advantageously to alleviate some of the problems encountered with the FIB milling of $\mathrm{Cu}$. Since ion channeling contrast is directly proportional to the sputtering yield, this contrast can be used as a guide to eliminate differential sputtering and reduce the effects of redeposition when milling is performed across a grain boundary or interface in polycrystalline or polyphase material. A modified cross section TEM lift-out technique has been established for use on crystalline interfaces using ion channeling contrast as a guide to create uniform milling properties across the boundary.

\section{ACKNOWLEDGMENTS}

This work was made possible through the generous support of Cirent Semiconductor, the I4/UCF/Cirent Partner- ship, AMPAC, and NSF DMR Award 9703281. The authors would also like to especially thank FEI Company and Micro Optics Incorporated for providing use of their equipment.

${ }^{1}$ B. I. Prenitzer, Ph.D. thesis, University of Central Florida, 1999.

${ }^{2}$ M. Nastasi, J. W. Mayer, and J. K. Hirvonen, Ion-Solid Interactions: Fundamentals and Applications (Cambridge University Press, Cambridge, UK, 1996), pp. 218-250.

${ }^{3}$ R. E. Franklin, E. C. G. Kirk, J. R. A. Cleaver, and H. Ahmed, J. Mater. Sci. Lett. 7, 39 (1988).

${ }^{4}$ R. R. Kola, G. K. Celler, and L. R. Harriot, Mater. Res. Soc. Symp. Proc. 279, 593 (1993).

${ }^{5}$ J. Lindhard, Phys. Lett. 12, 126 (1964).

${ }^{6}$ D. Onderdelinden, Appl. Phys. Lett. 8, 189 (1966).

${ }^{7}$ J. A. Sprague, P. R. Malmberg, G. W. Reynolds, J. M. Lambert, P. A. Treado, and A. M. Vincenz, Nucl. Instrum. Methods Phys. Res. B 24, 572 (1987).

${ }^{8}$ W. Palmer, K. Wangemann, S. Kampermann, and W. Hosler, Nucl. Instrum. Methods Phys. Res. B 51, 34 (1990).

${ }^{9}$ W. Hosler and W. Palmer, Surf. Interface Anal. 20, 609 (1993).

${ }^{10}$ J. F. Ziegler and J. P. Biersack, computer code TRIM (http:// www.research.ibm.com/ionbeams/home.htm\#SRIM, IBM-Research, Yorktown, NY, 1998).

${ }^{11}$ L. A. Giannuzzi and F. A. Stevie, Micron 30, 197 (1999). 